


\section{COVER STORY}
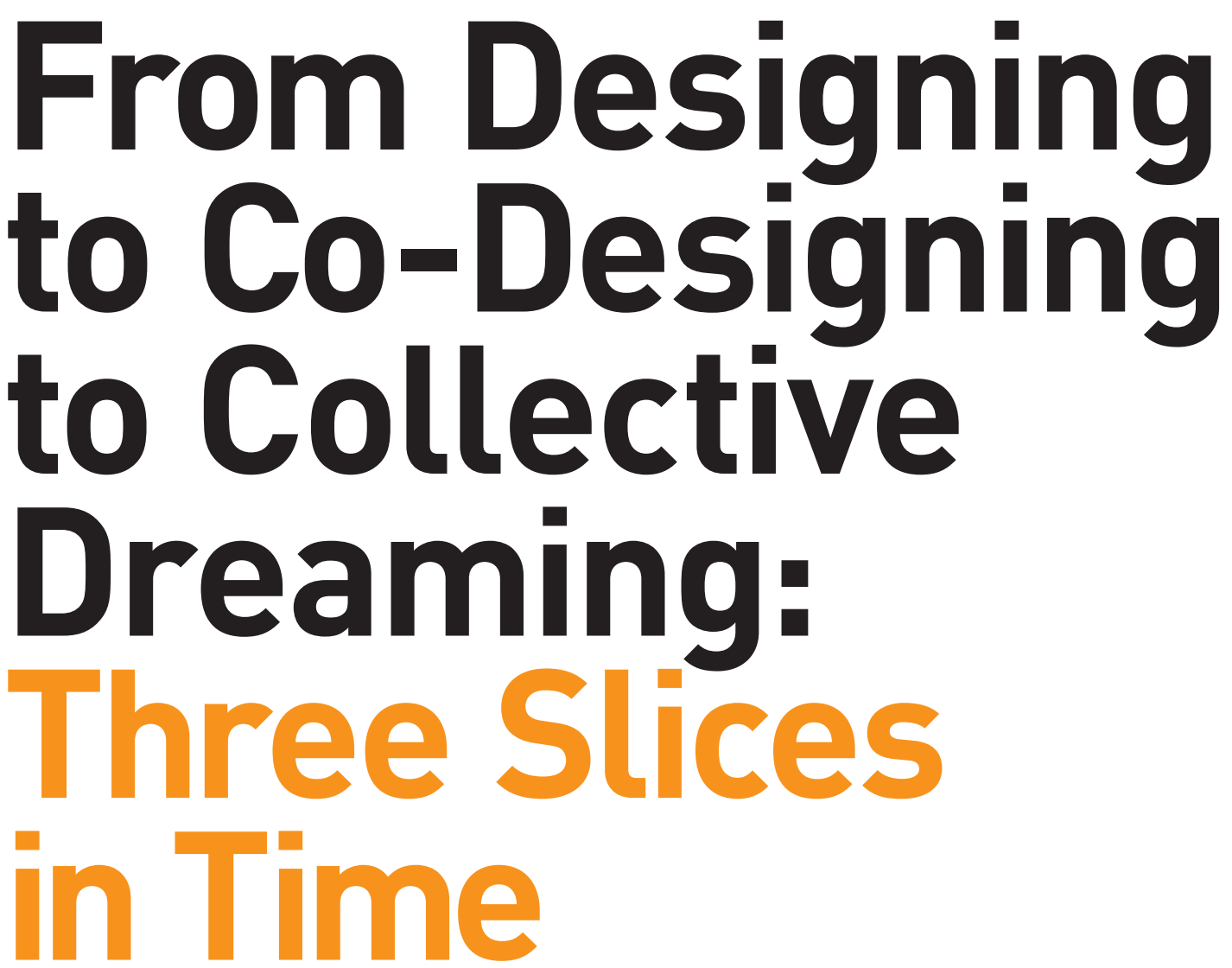

(4)

Liz Sanders, The Ohio State University and MakeTools

Pieter Jan Stappers, Delft University of Technology

\section{Insights}

$\rightarrow$ 1984: Designers did not

explore what to design.

They explored how to

design what the client

asked for.

$\rightarrow$ 2014: Designers and

design researchers

explore what to design,

not only how to design it.

$\rightarrow$ 2044: Designers and

design researchers work

to help ensure that what is

designed makes sense in

the future lives of people.
Over the past three decades we have witnessed shifts, connections, and reframings in just about every area of design: how design is done, who is doing it, for what goals, and what its results are. These changes show a move from the designing of things to interactions to systems, and from designing for people to designing with people and by people. In this article we look at the development of design practice over the past 30 years and then look briefly into the future, from a co-design perspective. Our goal is to sketch a map of how these ingredients hang together and to illustrate that with examples from cases and underlying principles.

Our perspective is informed by academic writing, but more so by our experiences with design practice in both industry and academia. Neither of us is a designer in the traditional sense; rather, we are practitioners and educators of co-designing. The observations here stem from many years of developing design research in the "fuzzy front end," connecting design research to conceptualization and development, and educating future co-designers.

\section{4: A SLICE IN TIME}

Let's start with a short list of historical 
THE WORD DESIGN CONSIDERED HARMFUL

Discussions about design can easily get confusing because the noun design is loaded

with different meanings and connotations. Here are a few of its definitions.

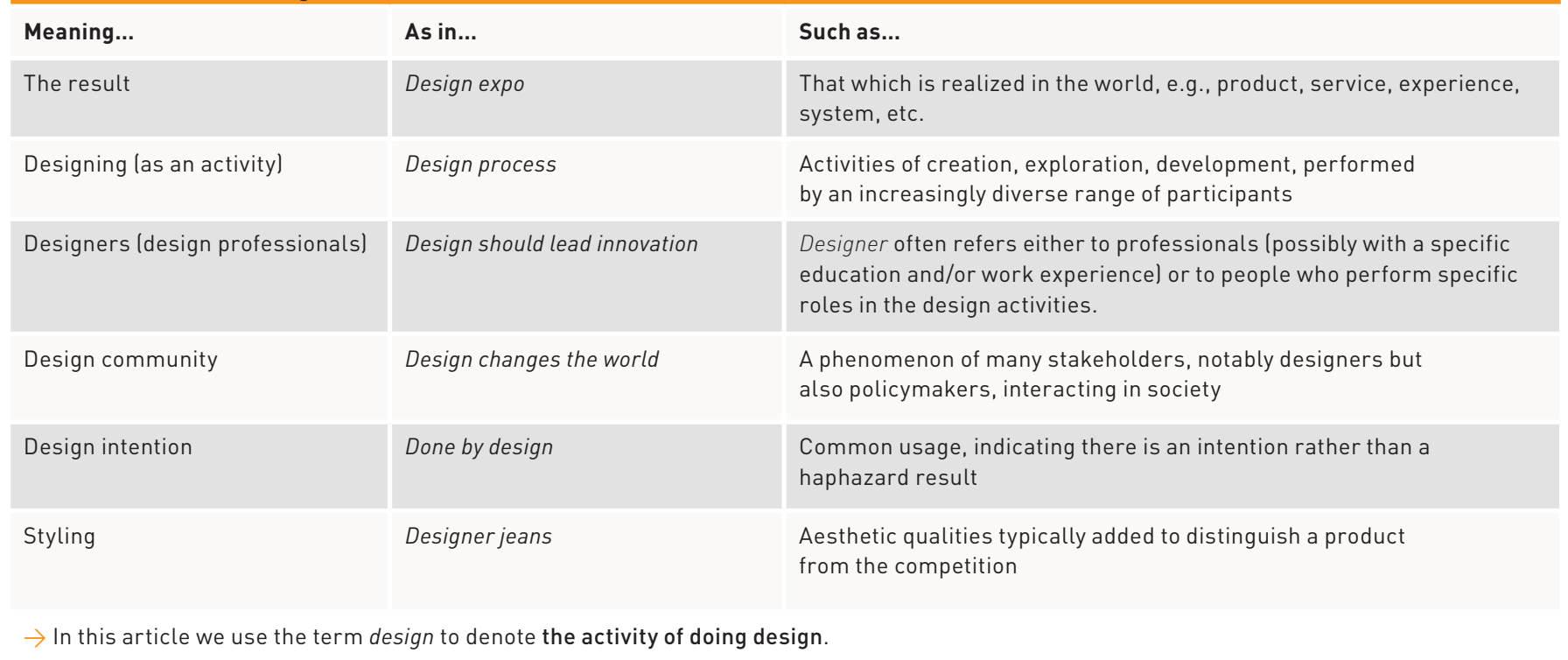

events that took place in 1984, in case you are not old enough to remember (or are old enough but have forgotten). Some of these events reveal how we worked and lived, and others were important for their impact on design culture:

- Apple Computer placed the Macintosh personal computer on sale in January 1984 in the U.S., launching it with a reference to Orwell's book.

- Consumers lined up to buy the first cellular phone, the Motorola DynaTAC 8000X, as soon as it hit the market. "The brick" weighed two pounds, offered just a half-hour of talk time for every recharging, and sold for $\$ 3,995$.

- Philips and Sony introduced the first commercial CD players. The Sony Walkman was by now five years old, the compact cassette 20 years old.

- Hewlett Packard introduced the first laser printer (HP Laser Jet) intended for the personal computer user.

- The Space Shuttle Discovery had its maiden voyage.

-A French immunologist identified the AIDS virus.

-William Gibson coined the term cyberspace in his science fiction novel Neuromancer.

- Ghostbusters was the year's topgrossing film in the U.S.

- TED was born in 1984 out of Richard Saul Wurman's observation of a powerful convergence among three fields: technology, entertainment, and design. But it wasn't online yet.

Human-computer interaction (HCI) emerged in the early 1980s, initially as a specialty area in computer science embracing cognitive science and human factors engineering.

How did we work? Communication at work was done either face-to-face, over the phone (including conference calls), or through regular mail. Federal Express was available and was commonly used in the business world, with the overnight letter having been introduced in 1981. The Internet as we now know it was not in use in 1984. Commercial Internet service providers began to emerge in the late 1980s and early 1990s, with the World Wide Web entering the picture in 1989. Most of us did not yet use computers at work. Microsoft launched the Windows operating system in 1987, so word processing software and spreadsheets were not yet widely used in 1984 . Secretaries were on staff to type on word processors what you wrote by hand on paper. Collaboration was not the dominant mode of getting work done; handoffs between people and departments were much more common.

Who designed? The design disciplines were practiced separately at this point in time, with firms specializing in domains such as industrial design, graphic design, architecture, or interior space design. Some very preliminary explorations into interdisciplinary design were just beginning. Interdisciplinarity in 1984 usually meant that different types of designers worked with each otherfor example, industrial and graphic designers collaborating to design on-product graphics. In Scandinavia, participatory design had been explored, but little of this had reached mainstream design practice.

How did they design, and what methods did they use? Sketches and iterative modeling were designers' main tools, although this varied by domain. For example, in the early conceptual stages of design, sketches were used by industrial designers, 
thumbnails by graphic designers, and tape drawings by automotive designers. Some designers took responsibility for the ergonomics of the product, design of communication materials, or interior space solutions. But designers rarely explored, understood, or addressed the cognitive, emotional, and social needs of people.

At this point prototypes tended to be built only in the final stages of a design process, resulting in very accurate representations of the physical aspects of the new product. Prototypes were mainly used in focus groups to get feedback on their sales potential. The "looks like" product mockup was also a useful tool for convincing the client that the concept was a good idea. Skilled model makers were often hired by design firms to produce highly refined prototypes.

\section{Who did research, and what} methods did they use? Market research was in full swing in 1984. (We should note that in 1984 the people served by design were referred to as customers or consumers. It was not until the early 1990s that the terms user and end-user came into widespread use.) In the early 1980s, if there was to be research done that involved current or potential customers or consumers, market research consultants were likely to be called in. But they were not likely to join design firms on a full-time basis. Their role was to help ensure that the stuff being designed and developed would survive in the marketplace. Their focus was on the tail end of the design and development process, after the conceptual development and the prototyping had taken place. Market researchers asked whether people would be interested in buying the product and how much they would be willing to pay for it.

In the early 1980s, design firms began experimenting with the social sciences. The experiment was design driven, with social scientists being brought in to serve the design process. For example, one of us (Liz) joined the design firm RichardsonSmith in 1982 as part of an experiment to see what would happen if someone with an education in psychology and anthropology collaborated with designers. In the 1980s she served as the spokesperson for the customer/ consumer and often evaluated design concepts with them. In addition, her role was to know and to empathize with the people who would use the product and to translate that knowing into principles and prescriptions that the designers with whom she worked could understand and use. Similarly, Jane Fulton Suri, who had an education in psychology and architecture, joined IDEO in 1987. By the late 1980s there were a number of social scientists who had entered the practice of design.

Such design researchers served as the interface between the designers and the customers, translating wants and needs into the language of the designers. The people who were the recipients of what was to be designed participated primarily as "test subjects."

What was designed? Designers (and sometimes design teams) were primarily responsible for the design of material artifacts: products, buildings, visual communication materials, and interior spaces. These designers were professionals who had been educated and then went on to practice in their respective domains. They were taught to believe they were the experts whose role it was to design for people. Clients came to the design team with a description of what was to be designed and what features it was to possess. Designers did not explore what to design. They explored how to design what the client asked for. Innovation was usually in the hands of the client and tended to be technology- or market-driven.

The marketplace served as the context for design, with success being defined by sales in the marketplace. Design awards were also important markers of success, more so in architecture than in other design domains.

New technology was invariably seen as a good thing and was eagerly applied in the form of new products and devices.

How were designers and design researchers educated? In 1984, most design schools offered degrees with specializations in, for example, industrial design, graphic design, interior space design, fashion design, and/or architecture. Design school graduates typically worked in the design discipline in which they had been trained. Sometimes industrial designers learned about ergonomics, but most schools did not offer a separate course in design research. There were no undergraduate schools that specialized in educating design researchers in 1984. Ph.D. candidates

\section{THE MANY RELATIONS BETWEEN DESIGN AND RESEARCH}

Doing design and doing research are both activities that are aimed at a "better" future, and their relationship has been discussed and debated profusely. Both build on earlier knowledge, both connect to the empirical world, and both proceed through iterations of planning and evaluating. Many find it makes sense to distinguish them by their intended primary result (for design it is a new, specific, product or service; for research it is new, generalized, knowledge).

The term design research has two different meanings: In practice it usually means research that is performed as a part of doing design, notably research about and involving users. In academia, it can also mean research about how designing is done, notably about design methods and processes. In this paper, we use the term to mean the former.

Finally, the term research design is used in many sciences to indicate the structure or method followed in a particular study, e.g., experimental design.

There are four different relations between design and research as diagrammed below: (i) overlapping collaboration, differing in results, as mentioned above, (ii) research as an important ingredient in design education and practice, (iii) design as a part of research, as in research through design (e.g., [8,9]), and (iv) the traditional notion that design and research are done by different professionals and cause a conflict of roles.

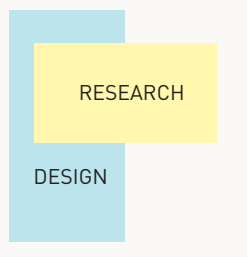

collaboration and similarity

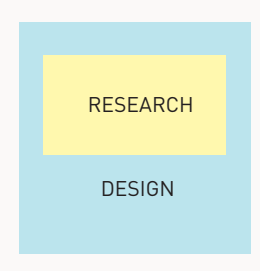

design research

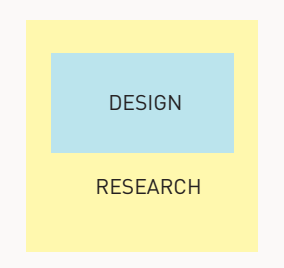

research through design

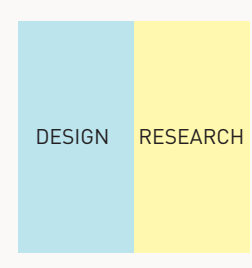

traditional separation 
with design training were extremely rare and typically had to do their Ph.D.s in other disciplines.

INTERIM EVENTS (1984-2014)

The shift from seeing people as consumers and customers to seeing them as users began with the advent of PCs that were difficult to use. Microsoft was a pioneer, with a team of four people doing usability engineering in 1988 [1]. Usability testing grew rapidly once PCs and Macintoshes became available to everyone who could afford them. The cognitive needs of the user, in addition to the previous concern with ergonomics, became major concerns in the 1990s.

The ongoing integration of design research into design practice moved fastest in industrial design and user interface design, where it was practiced according to a usercentered research approach. With the user-centered approach, designers still designed for people, but their perspective on people enlarged from seeing them as customers and consumers to seeing them as users of products and interfaces.

In the user-centered design process, we focused on the thing being designed (e.g., the object, communication, space, interface, etc.), looking for ways to ensure that it met the needs of the user. In user-centered design, the roles of the researcher and the designer were distinct yet interdependent. The user was not really a part of the team, but was spoken for by the researcher.

An ongoing battle was being played out in the early 1990s between the user-centered design researchers and the market researchers. User researchers focused on helping the design team to make products, communication, and spaces that were useful, usable, and desirable. Market researchers focused on the delivery and sales end of the process. Their goals were complementary, but the different groups were often competing for the limited funds available for research.

Over time, design research activities slowly moved to the front end of the design development process, where designers and design researchers were getting involved with challenges at larger and larger levels of scale. The challenges ranged from automating ticket sales to enhancing the experiences of passengers waiting at airports to the orchestration of collaboration in healthcare services to attacking societal issues like obesity. The means - originally the object of design-became the second step in the designers' work. Interest in design research grew as the challenges became more and more demanding, particularly at the front end of the process. Soon designers and design researchers were being called upon to get involved in exploring what to design, not only how to design it.

Many new methods and tools for design research were developed, particularly from 1999 on. A number of books that organize and describe large collections of design and design research methods and tools began appearing.

\section{4: A SLICE IN TIME}

We won't start this slice with a list of historical events, because we all live it today, but let's just do a comparison:

- Smartphones, social media, and other forms of connectivity have spread through our lives.

- Digital means, increasingly "the cloud," have almost eradicated regular mail for the purposes of transferring information.

- Global problems of demographics, resource depletion, healthcare, and new ways of organizing civic society"creating livable circumstances"-are prominently in the public's awareness.

- New technologies no longer originate only in the Western world; Asian countries and companies have integrated as active players in the innovation-sphere.

Not only have our methods of working changed, but the mindset in 2014 has also shifted toward that of designing with people. We see this for both the long-term challenges that address societal issues and the shortterm challenges of the marketplace. Design and design research are now more integrated, especially in the newer domains of practice such as systems, service, and social design.

How do we work today? We live in two worlds: One is real and the other virtual. These worlds are tightly coupled for many people. Small, fast, and mobile devices keep us connected to each other in real time. The Internet is available to anyone with a wireless device. Many people sleep next to their smartphones, and young people have altogether abandoned landline phones and wristwatches. Children as young as three or four can use the new devices without much explanation.

We work in teams both real and virtual, and we can collaborate anytime and anywhere through our connected devices. We have many different ways of communicating with the others on our teams, including face-to-face meetings, emailing, Skype and other video chat services, Twitter, Facebook, the phone (including conference calls), and so on. We can collaborate in real time at different locations using shared documents. We are able to participate in just about anything that catches our attention at levels of scale not previously imaginable, thanks in part to the prevalence of social networks. At the same time, enthusiastic and uncritical application of new technology over the past 30 years is now recognized as having created new problems and left others unsolved. But we continue to let new technology push innovation and drive design.

Innovation no longer comes from just market pull (what people ask for) or technology push (what is invented), but also from a contextual push [2], 
Skeptics of co-design still cite the famous Henry Ford quote-if you asked users what they wanted, it would not have been a car but "a faster horse"-as evidence that participation in design should be limited to a narrow set of professionals. But more are now realizing that facilitating the participation of users and other stakeholders involves far more effort than merely asking them "what they want."

Over the past decades, techniques have been developed to involve people as "experts of their experience" [10]. Here are two principles we have found essential in getting at the underlying user values that can inspire the design of future ways of living. In the book Convivial Toolbox [3] we, together with some 50 colleagues, describe our experiences with these principles and tools and the techniques that build on them.

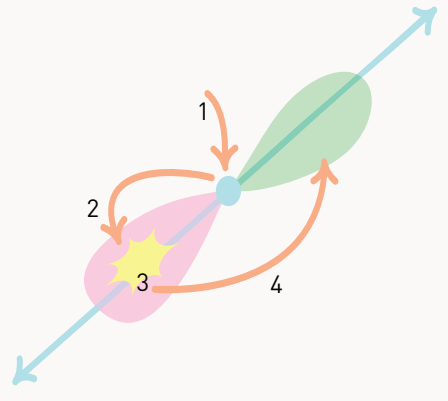

The path of expression is the structure of the process of sensitizing and awareness-building, by which design researchers guide participants to a deeper understanding of their needs, wants, hopes, and dreams in order to identify criteria and opportunities. It takes the participant from considering the present situation to identify what ingredients are important (1), to then recalling previous good and bad experiences (2), which are reflected on to find underlying values (3), which are then taken to guide thinking of what would be a desirable future situation (4).

through studies that deliver insights about what people might want or need in the future. Companies study lifestyles and people's needs to come up with new products. An example from the Netherlands is the Senseo pods, where coffee company Douwe Egberts had done user studies on coffee preferences and found that people preferred single cups and different flavors. The company also noted a trend that more people consumed coffee by themselves, and that in taste panels many people liked a creamy top. It resulted in new coffeemakers, new distribution forms for individual-portion pods, new forms of co-branding, and new shelf space in stores. There was no market pull - no people asking for coffee pods in the shops - and it wasn't because of a new technology.

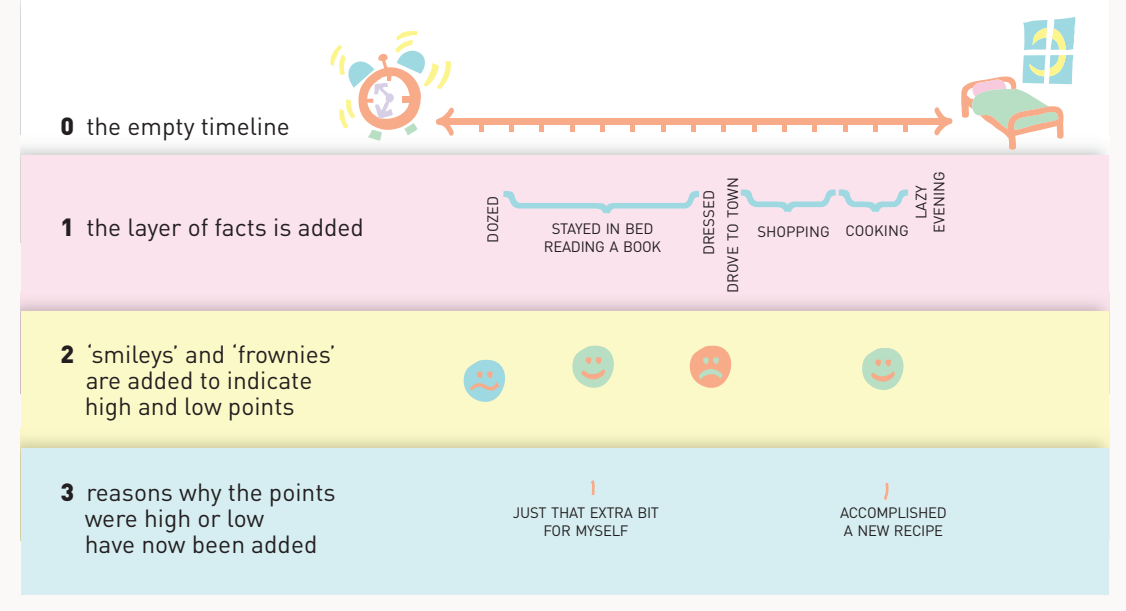

\begin{abstract}
Part of that awareness concerns people's values. Again, instead of bluntly asking, "What are your values?" participants can be guided to discover their values by leading them to record facts, remember their emotional valence, and then think of the underlying reasons. In the timeline exercise, each element in each layer is constructed on the basis of comparisons across the entire previous layer.
\end{abstract}

Who designs? The design disciplines have become more integrated, with interdisciplinary design teams now commonplace in many industries. Others joining the design team include design researchers, businesspeople, marketing representatives, and engineers of various sorts.

Design research is now practiced all along the design development process, but most of the growth is taking place at the early front end, also known as the fuzzy front end, where the strategy and direction and the "what" of the development effort are designed. The roles of designers and design researchers are also blending together and converging to the point where it can be hard to tell them apart. This is especially true at the fuzzy front end.

Co-design in various forms, from participatory design to co-creation, has attracted the interest of many people, companies, and organizations, and is growing rapidly. Designers and design researchers are exploring the creation of tools that nondesigners can use to channel their own creativity. In co-design, designers use the ideas generated by others as sources of inspiration and innovation. Designers are becoming part of teams responsible for the generation, analysis, and interpretation of the "data": the artifacts and models that result from the co-designing process. Design professionals are learning the skills needed to act as facilitators of the collective creativity of others.

How do they design, and what methods do they use? User-centered design is still very strong in UX practice. But co-design is now 


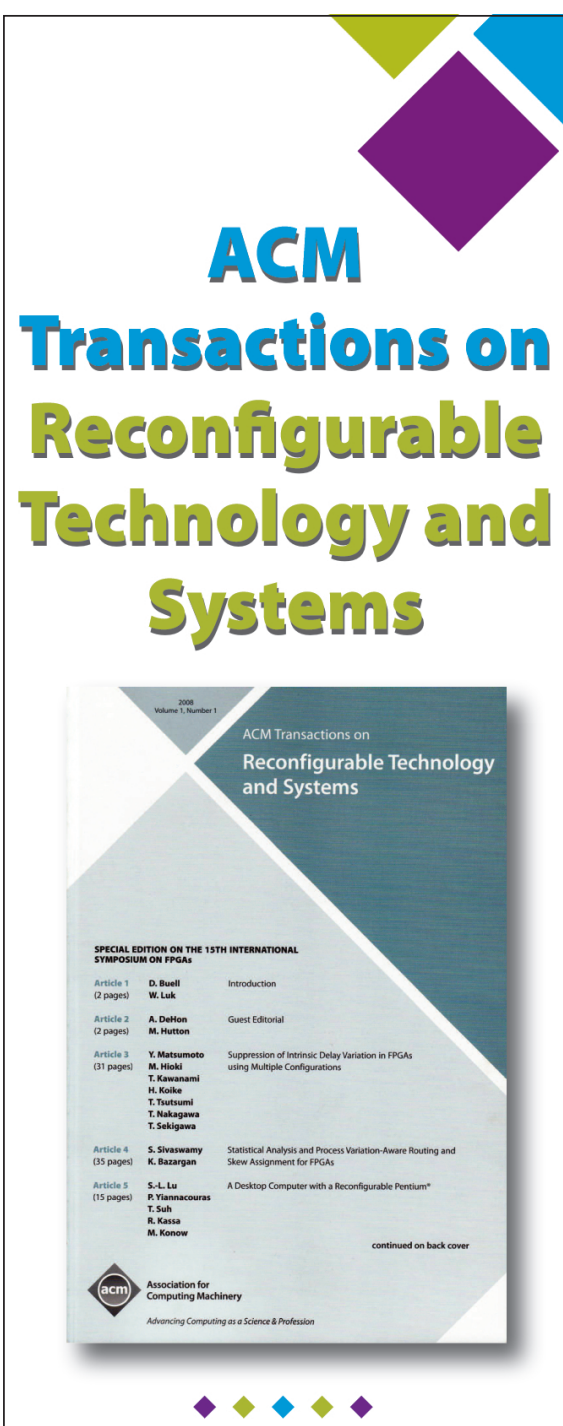

This quarterly publication is a peerreviewed and archival journal that covers reconfigurable technology, systems, and applications on reconfigurable computers. Topics include all levels of reconfigurable system abstractions and all aspects of reconfigurable technology including platforms, programming environments and application successes.

\section{www.acm.org/trets www.acm.org/subscribe}

emerging as the dominant practice in other design domains, particularly in newer areas such as social and service design. The traditional mindset of designing for people still operates in architecture and fashion design.

Co-design is practiced using a designing-with mindset. There is growing interest in and support for this mindset that the end-users are the experts of their future lives and that designers/design teams can design with the people. It is a growing recognition of and skill at involving end-users in design processes as "experts of their experience," and a recognition that this requires a process rather than a one-shot reaction. (In our 2012 book Convivial Toolbox [3], we describe co-design tools and techniques and their underlying principles - see sidebar).

Furthermore, it is now recognized that the end-user is only one person among others whose needs and dreams need to be addressed in product/ service development. For example, other roles include caregiver, trainer, purchaser, back-office worker, maintainer, assembler, and bystander. It is also now acknowledged that all levels of people's needs should be addressed, including ergonomic, cognitive, emotional, social, and cultural needs.

Many people have become uneasy about terms like user, consumer, and client, which pin people down in narrow and restrictive roles. At this moment, we refer to them as participants and partners, or just people, to express the multiple roles and perspectives that are needed.

Who does design and research at the front end, and what methods do they use? For the design researcher who uses a designing-for mindset, interviews and observations are still the predominant tools for conducting research. For those who use a designing-with mindset, the toolbox is virtually unlimited. New methods, tools, and techniques are being invented or reinvented on a daily basis. The participatory prototyping cycle of making, telling, and enacting is a way to organize and activate the dozens of old and new tools for bringing people into the design development process.

What is designed?

Interdisciplinary design teams are now responsible for design at several levels of scale. They are still responsible for the design of tangible things, such as products, buildings, visual communication materials, and interior spaces. However, the context for design has expanded to also include the social realm through the design of intangible services, interactions, user experiences, systems, interventions, behavior changes, transformations, and so on. Designers are part of diverse multidisciplinary teams tackling crucial societal issues such as obesity, resource scarcity, and aging populations. Designers and design researchers are at work at the fuzzy front end to help ensure that what is designed makes sense in the future lives of people.

Success is no longer defined primarily by monetary value such as sales in the marketplace. Beyond monetary value, we now see experience value, the objective of which is to meet the wants and needs of people, as well as social value, the objective of which is to be able to deliver on more sustainable and convivial ways of living [4].

\section{How are designers and design} researchers educated today? Change has been slower on the academic side. Most design schools still offer degrees with distinct specializations such as industrial design, graphic design, interior space design, fashion design, and architecture. At the same time, we see new programs focusing on goals rather than means, such as design for sustainability, design for experience, and design for service. Typically, design research (in both senses - see

\section{In 2044, technology will be seen as a tool to serve people, rather than primarily as a means to produce products for profit.}


sidebar) is still not a large part of the program. There are no schools that focus on the education of design researchers at the undergraduate level and just a handful that focus on it at the graduate level. But this is rapidly changing. In Delft 10 years ago, individual design students explored generative and other participatory design methods. Over the past decade they became part of the mainstream curriculum and focus of research. Designers are now educated at the graduate level with a basis in general design methods as well as more knowledge from social sciences and more emphasis on facilitation and research than in earlier years. But by and large, designers and design researchers are finding their own way.

Design graduates are not necessarily working in the design discipline in which they had received training because there are so many other options, such as interaction design, social design, and service design. Service design, in particular, requires the collaboration and integration of many disciplines.

\section{4: A SLICE IN TIME}

Obviously, creating a bulleted list of how we will live in 2044 is guesswork, but we will go ahead and speculate about (not predict) how we will live, work, and design in the future. Those who read this now will probably have a tough time in 2044 coping with the new mindsets and ways of being, just like those who thrived in a paperbased world in 1984 are uneasy with all the changes now.

First and foremost, design will play an increasingly large and significant role:

- Everyone designs.

- Design is a collective activity.

- Funding for frugal innovation [5] has surpassed funding for technological innovation, with the funding sources coming from collaborations between the public and private sectors.

-We understand the need for a balance between the real and the virtual ways of living and working, and we know how to achieve it. However, not everyone chooses to stay in balance.

- Arts and crafts that were traditionally practiced by either males or females have intersected and

\section{EMERGING AREAS FOR DESIGN RESEARCH AND PRACTICE}

Service design and design fiction are just two of the emerging areas for design research and practice that are receiving attention. This figure positions a number of the new approaches relative to each other and across different timeframes. Movements of design are emerging across timescales: the world as it is (inner ring), the near future (middle ring), and the speculative future louter ring).

Note that the diagram is radial and positions the designing-with mindset on the right and the designing-for mindset to the left. The diagram shows where service design and design fiction sit in relation to the other trends and approaches. At the center of the diagram is the traditional core of designing. The three timeframes emanate outward from the core. The first layer around the core refers the world as it is, the second layer to the near future, and the third layer to the speculative future.

In the segment to the right, service design and social design are usually seen as manifestations of the intent to serve people. In the middle, user experience and embodied interaction aim to engage people. In the segment to the left, design interventions and critical design intend to provoke or stir people up. Design fiction sits midway between engaging and provoking on the outside layer of the speculative future. What will sit between serving and engaging in the speculative future? (Adapted from [7])

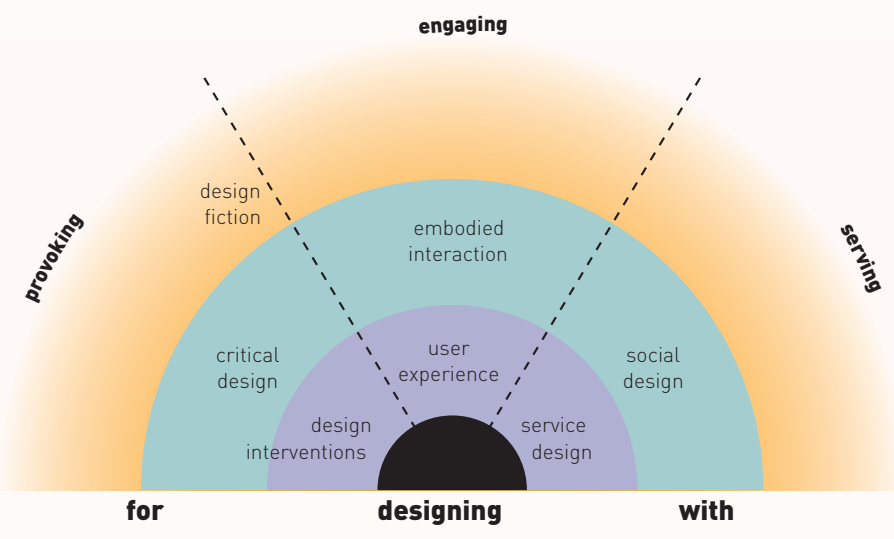

\section{MAIN STORY DIAGRAM}

This diagram gives an overview of the storylines we discussed.

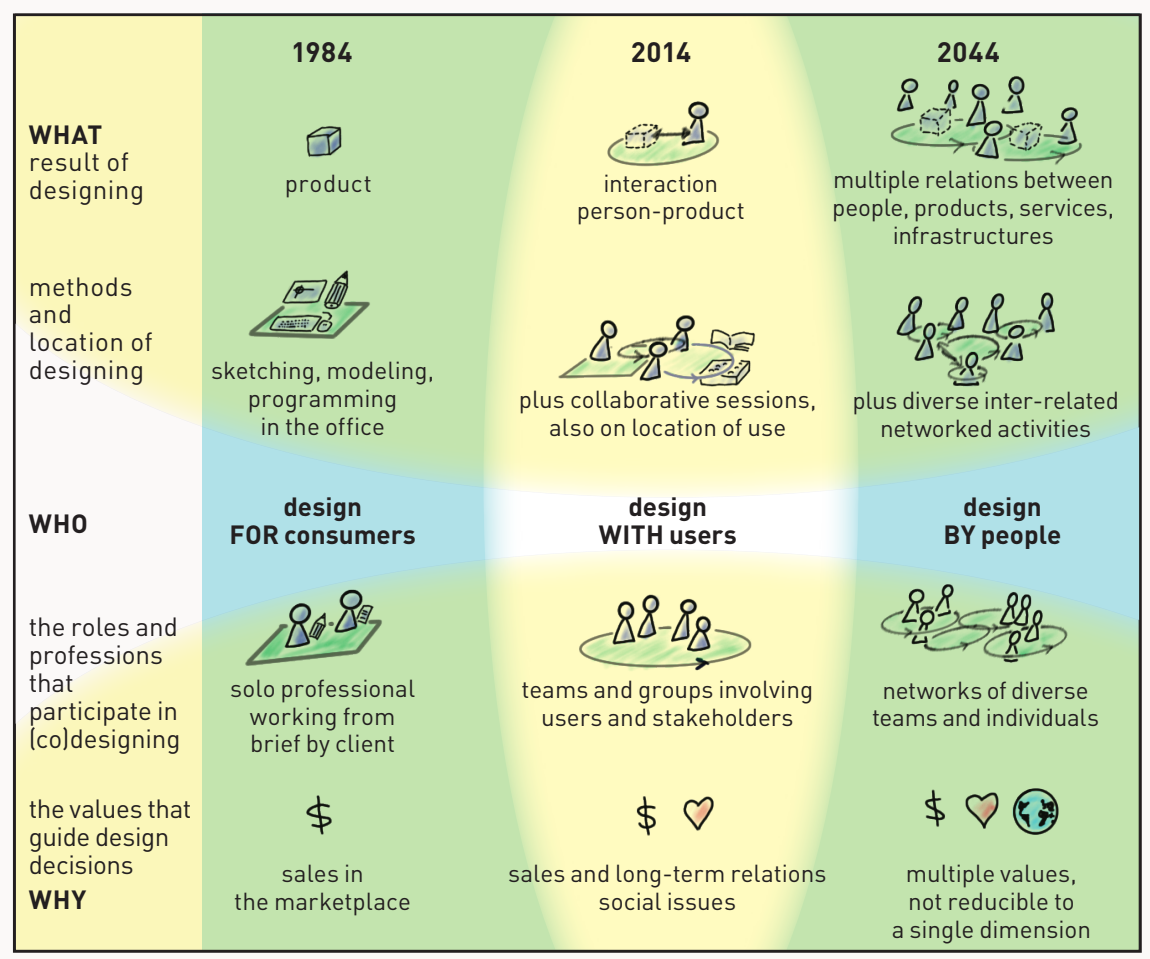




\section{COVER STORY}

exploded into a very wide and creative range of "transgendered" art and craft practices.

- Healthy foods are available and affordable for everyone in the developed nations, and the situation in other parts of the world is improving rapidly. McDonald's is no longer in the food business.

- The options available for primary and secondary education are staggering.

- Education at all levels has not only caught up to change but now actually leads change.

Complexity, interdependence, and a shift of where we are constrained and where we need to be flexible allow and require everyone to contribute to the co-design of future ways of living. People from all walks of life understand what designing means and can choose to become involved as participants or catalysts in the process. They can, of course, choose not to become involved and accept what others are able to imagine and execute. For example, healthy food is available and reasonably priced for everyone, but that does not mean everyone chooses to live a healthy life.

How will we work? Intangible and virtual modes of communication dominate. But we understand the dangers of living entirely this way and have learned to value and celebrate the special qualities of face-to-face and hands-on modes of interaction. To prepare for the ways we will live and work in 2044, we have created a wide variety of learning environments for children that prepare them to be proactive members of both tangible and virtual communities.

Technology will be seen as a tool to serve people, rather than primarily as a means to produce products for profit. Success will go hand-in-hand with sustainable and convivial ways of living. We see growing interest in frugal innovation, or "designing products specifically to meet the needs of the world's poorest people." We have passed the point of "overengineering and underengagement with the end user" that was characteristic of so many attempts at social innovation in the early 2000s [5]. A whole generation of socially minded Millennials is now running the show.
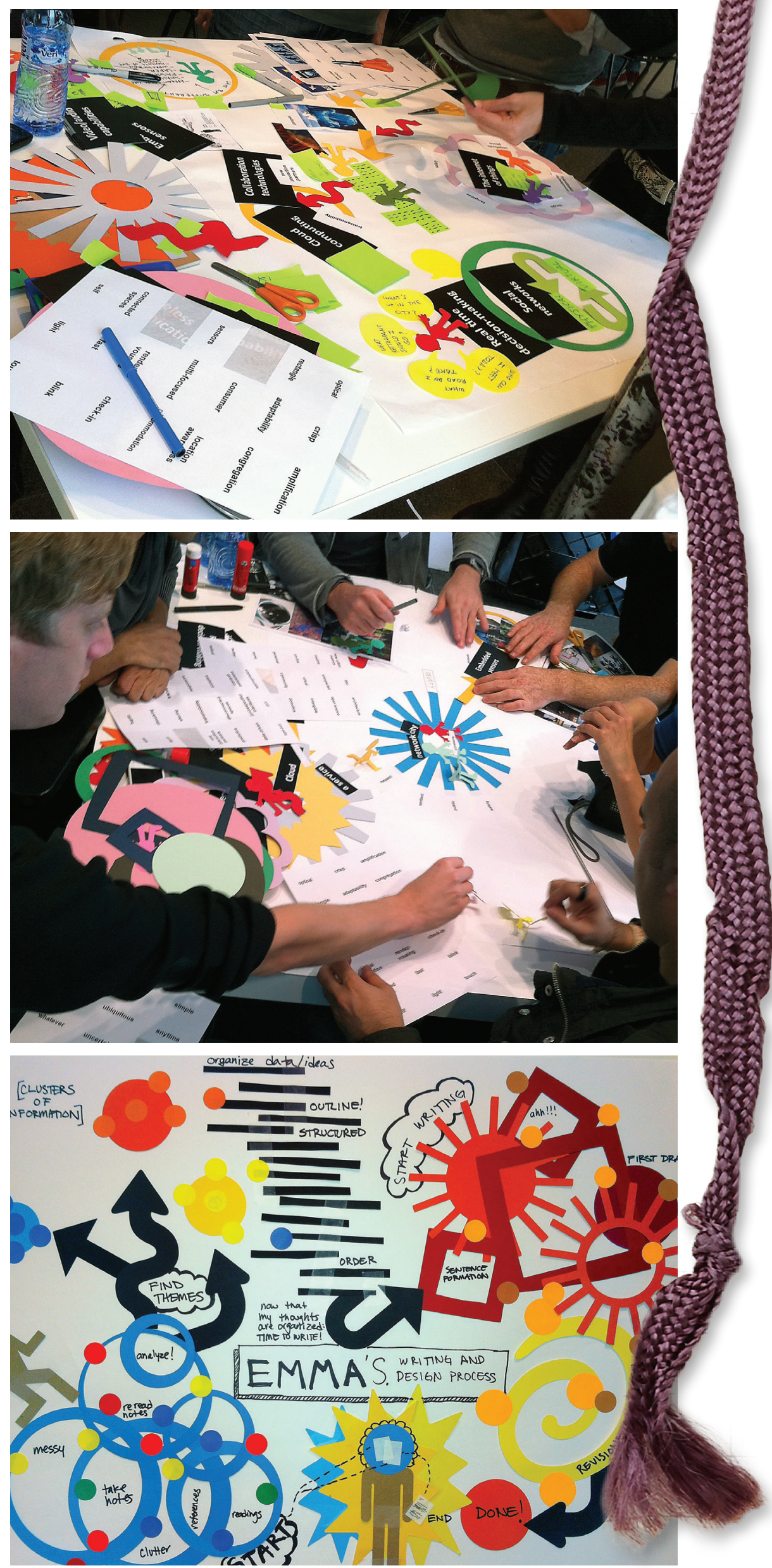
Design and design research are one and the same at the front end. The front end is transdisciplinary, and the problems that designers and design researchers find themselves involved with are wicked, in the sense that there is no sharply specified problem or no simple criteria for a single solution. Rather, problem solving is a complex process of sensemaking and intervention, with spinoffs along the way [6]. Transdisciplinary social networks of people work collectively to address wicked problems across continents. Success goes hand in hand with sustainable and convivial ways of living.

Who will design? Everyone can be involved in designing and gains relevant learning experiences throughout their education to enable their participation. The people whom we currently call designers are the toolmakers, making the tools and providing the materials the rest of us use to imagine and express our collective ideas about future experience. These toolmakers focus on making sense of the future as well as on giving shape to the future [7].

What will be designed? The people who are today's designers and design researchers are the facilitators and shapers of the collective dreams of the people in 2044 . We now understand the intricate relationships between the three levels of value in co-designing (i.e., monetary vs. experience vs. social values) and we know how and when to promote each. The success of a project is judged on a complex set of qualities; the old bottom line of financial profit will be difficult to discern in the complex business models that incorporate the indirect effects and feedback loops needed to manage the networked society.

\section{How will people be educated?}

Elementary school children learn about designing and co-designing through practical and fun handson experiences. They have classes, events, and workshops in making, repairing, reusing, and repurposing. Hacking comes later, in middle school. There is no gender tag on the creative domains. Boys learn to knit and sew while girls make interactive things and things out of wood. The educational standards for assessment have been reconceptualized. The focus now is on multicultural, social, and humanistic levels of achievement as the foundation for the traditional skills of reading, writing, and arithmetic.

Older schoolchildren have learning experiences that provide activities of co-design thinking and making. They initially learn by co-designing with each other. By the time they graduate from high school, they will have learned how to bring others together in co-designing efforts. What we used to call service learning at the high school level now consists of experiences in participatory design with members of the local community.

At the university level, designing is a core component of all curricula in every department. The design process is the path that we take to go between and open the doors to the disciplinary silos. Faculty members are rewarded for transdisciplinary successes as well as for discipline-specific goals. Some students will choose to focus their education on design and learn the skills and frameworks of hybrid designer/design researchers. They can choose whether to focus on a practical route or an academic route. Those who aim to go into practice will learn how to make tools and select the materials to facilitate the creativity of others. Those who choose the academic route will explore and experiment with complex social systems in collaboration with students from across the world through socially engaged networks. Students can also choose to have feet in both camps if they plan to practice and teach others who aim to enter practice.

\section{CONCLUSION}

Over the past 30 years, almost every aspect of doing design has changed. We still seem to be in the middle of a transition to greater entanglement and complexity, but with greater involvement of people and, hopefully, more value contributed by the design capabilities of many. We can anticipate these uncertainties with hope or fear. But if we can use design thinking, making, and enacting to visualize and explore the future together, then we will be able to harness our collective creativity to serve our collective dreams.

\section{ENDNOTES}

1. Sanders, E.B.-N. Ethnography and the empowerment of everyday people. White Paper for Microsoft Corporation, 2004.

2. Stappers, P.J., van Rijn, H., Kistemaker, S.C., Hennink, A.E., and Sleeswijk Visser, F. Designing for other people's strengths and motivations: Three cases using context, visions, and experiential prototypes. Advanced Engineering Informatics 23, 2 (2009), 174-183.

3. Sanders, E.B.-N. and Stappers, P.J. Convivial Toolbox: Generative Research for the Front End of Design. BIS Publishers, 2012.

4. Sanders, L. and Simons, G. A social vision for value co-creation in design. Open Source Business Resource. Dec. 2009; http://www.osbr.ca/ojs/index.php/osbr/ article/view/1012/973

5. Bansal, S. Innovation within reach. The New York Times. Aug. 21, 2014; http://opinionator.blogs.nytimes. com/2014/08/21/innovation-within-reach/

6. Rittel, H.W.J. and Webber, M.M. Dilemmas in a general theory of planning. Policy Sciences 4, 2 (1973), 155-169.

7. Sanders, E.B.-N. and Stappers, P.J. Probes, toolkits and prototypes: Three approaches to making in codesigning. CoDesign 10, 1 (2014), 5-14.

8. Zimmerman, J., Forlizzi, J., and Evenson, S. Research through design as a method for interaction design research in HCI. Proc. of the SIGCHI Conference on Human Factors in Computing Systems. ACM, New York, 2007, 493-502.

9. Stappers, P.J. Doing design as a part of doing research. In Design Research Now. R. Michel, ed. Birkhäuser, Basel, 2007, 81-91.

10. Sleeswijk Visser, F. , Stappers, P.J., Van der Lugt, R., and Sanders, E.B.-N. Contextmapping: Experiences from practice. CoDesign 1, 2 (2005) 119-149.

\footnotetext{
(4) Liz Sanders has a background in psychology and anthropology. Over the past three decades, she has practiced co-designing across all the design disciplines, developing methods, tools and techniques to drive and/ or inspire design from a human-centered perspective. She is the founder of MakeTools, a company that explores new spaces in emerging design landscapes. She also teaches in the Design Department at The Ohio State University.

$\rightarrow$ lizamaketools.com
}

(1) Pieter Jan Stappers is professor of design techniques at Delft University of Technology's Faculty of Industrial Design Engineering. His research has focused on developing tools and techniques that support the early phases of design processes. Together with colleagues and Ph.D. students, he leads the contextmapping research initiative in Delft, developing design research methods and tools and bringing these to education and practice. $\rightarrow$ p.j.stappersatudelft.nl 